\title{
Effect of Using Video on Learning Skill of Emitting in Table Tennis
}

\author{
Ibrahim Abdul Ghani Salameh ${ }^{1}$ \\ ${ }^{1}$ Faculty of Physical Education and Sport Sciences, Hashemite University, Jordan \\ Correspondence: Ibrahim Abdul Ghani Salameh, Faculty of Physical Education and Sport Sciences, Hashemite \\ University, P. O. Box 150459, Zarqa 13115, Jordan. Tel: 962-7-7753-0911. E-mail: dribrahem@yahoo.com
}

\author{
Received: October 7, 2013 Accepted: February 26, 2014 Online Published: March 31, 2014 \\ doi:10.5539/ass.v10n7p182 URL: http://dx.doi.org/10.5539/ass.v10n7p182
}

\begin{abstract}
The study aims to examine the effect of using video on learning skills of fore and retro-emission in Table tennis. The sample of study consisted of 40 students of the table tennis course at Hashemite University. The results of the study showed that using video has a positive effect on learning process. It develops the skill of both fore and retro-emission in Table tennis. The results also showed that the effect of using video is the best method of learning the skills of both fore and retro-emission. In addition, this leads to this learning program by video is a useful method in learning the skills of Table tennis.
\end{abstract}

Keywords: skills, table tennis, video, emitting

\section{Introduction}

Educational operation preoccupies researchers concerned with education nowadays. It depends on a group of educational experience at the instructor, and relates to the content of educational subject and how to communicate with students, conveying information by instruments and variant means of education, concerning the best using of information technology. Putting in mind consizing time and effort. Styles and different methods of education are considered important matters. The instructor or the physical trainer should put in mind to achieve the objectives of the educational operation. He should be proficient to promote the educational operation, with different skills, observing concise in time and effort. Dealing with beginner students, as it is with accepted students at faculties of physical education, needs a great effort and time to convey information to them and achieve the aim of educational operation (Al-As'ous, 2001; Singer \& Peose, 1976).

Many researchers indicated to sharing offered by educational means in submitting assistance to students of different ages and stages of learning, and machinery of acquiring the performance, or good agreement with movements and variant physical educations. For educational means met a big role in learning operation and education in general and motional learning in particular. Their using assists mastering the motional skills; together with the instructor and physical trainer on varying styles of education and training taking the educational operation out of monotony and boredom. takes it to excitement and attracts attention and heightens students' level (Al-Masri, 1997) for example, many basic skills in the table tennis need plenty of preparation, effort and developed educational and assisting instruments, enabling the instructor, or physical trainer increase effectiveness of the level of learning (Salameh, 1999).

Movements that performance of basic skills demands in the table-tennis depends on how to execute the correct performance, built on principles of education and training, clearly done during different conditions of playing. Therefore, giving the correct referee on the individual through hoped results from the educational operation, and so applying all technical and skillful plans concerning the game.

\section{Problem and Significance of Study}

Operation of preparing individual at an integrated form and well balanced from all personal sides (physical, skillful, Social mental, psychological, and emotional) is considered from the objectives of physical education with all its activities and different types. Significance of this study comes from concentration on the best employed styles in the educational operation at some skills of the table-tennis for the University stage in particular, and through the session of the physical education and the variant physical activities in both sides; the practical and the theoretical, through which we aspire to assist the student to understand, grasp and implement variant skills. It is an objective should be achieved. The instructor should use all methods and different educational means, which enrich the learning operation and create the element of excitement inside students, and 
assist in elevating students' level in the different sides, which achieve innovation and destination (Singer \& Dick, 1980).

Skill of emission in some physical games, especially the table-tennis is considered one of the basic skills, that have clear effect in getting a goal result, for it will assist in winning at rate of $(\% 50)$ if done in a correct way. from experience of the researcher as an instructor in the Ministry of Education, trainer of the table-tennis and a university professor lecturing in the course of the table-tennis, noticed that there is a clear weakness in the way of teaching some skills of the table-tennis and acquiring the students the technical skill, views that some educational means should be used, such as the video as considered to illustrate the correct technique to perform the skill through witnessing and implementation. This is considered from the basics to acquire students the skill properly. And the researcher seeks to treat the problem of disperforming the skill at the technical method, considering the educational means a basic part of the educational operation, mastering the required and observing regulations and rules of the games. That is, for observing factors of security and safety and recognizing the best way of teaching to protect health with what fits reality of students, and the level of their abilities, and acquiring them the skills of table-tennis at a plain and accessible way and staying far away from complication during implementation and performance. The skill of emission was chosen as considered the main part of the basic skills. Therefore, the researcher found that the best way is to employ the video to learn skills of the table tennis.

\section{Objectives of the Study}

This study aims at:

1) Exploring the effect of a suggested educational program on learning both skills of fore and retro-emission in the table tennis by individuals of the disincentive group.

2) Exploring the effect of a suggested educational program by using video on learning both skills of fore and retro-emission in the table tennis at the individuals of the experimental group.

3) Exploring differences between both experiments prior and posterior between both groups of study (the disincentive and the experimental) in learning both skills the fore and retro-emission in the table tennis.

\section{Hypotheses of Study}

1) There are differences with statistical indication at the level of $(\alpha \leq .05)$ between the fore experiment for the interest of the retro experiment at the disincentive group in learning both skills of fore and retro-emission.

2) There are differences with statistical indication at the level of $(\alpha \leq .05)$ between the fore experiment and the retro experiment for the interest of the retro at the experimental group in learning both skills of fore and retro-emission.

3) There are differences with statistical indication at the level of $(\alpha \leq .05)$ in the retro-experiment between the disincentive group and the experimented group for the interest of the experimental group in both skills of the fore-emission and the retro-emission in the table tennis.

\section{Previous Studies}

Salameh and colleagues (2007) conducted a study aimed at exploring the effect of using two styles in educating some skills of the table tennis at a level of learning the basic stage. The study of command and the style of training in learning both the fore-lifting beat and the retro-lifting beat were used. Also reconnoitering the best style in learning these skills on a sample consisted of (60) students for the basic stage in Zarqa Governorate. The study deduced that the command style and training style have a positive effect in learning both skills of the fore lifting beat and retro lifting beat. The training style is more appropriate in learning the retro-beat, and the command style in learning the fore beat.

Al-As'ous (2001) made a study aiming at reconnoitering the effect of using the assisting instruments in developing some basic skills in the table-tennis (chest passing, shiftiness, directing from firmness in one hand) where the sample of study consisted of (3) students, divided into two groups: one is disincentive and the other experimental, where the training program was implemented (1) by using assisting instruments against the experimental group, (2) which used the assisting instruments to develop the basic skills in the basketball.

Salameh (2004) made a study aiming at reconnoitering the effect of using the video in learning both skills from the above-tennis and passing from above to front in the volleyball. This study was done on a sample consisted of (20) female students from the volleyball courses in Hashemite University. The results of study deduced that there are differences with statistical indication at the level of $(\alpha \leq .05)$ in the level of skillful performance to emitting from the above-tennis between the fore and retro-experiment for the interest of retro-experiment at the 
experimental disincentive group, and also there are differences with statistical indication at the level of $(\alpha \leq .05)$ in the level of skillful performance at the experimental disincentive group.

Al-Deiri and Abu Ruz (1994) prepared a study aimed at reconnoitering the effect of using the video on learning the skillful performance of the snatching lift in the game of weight lifting at students of the faculty of physical education. The sample of study was divided into two groups: the disincentive group and the experimental group. The results showed that there are differences with statistical indication between the two groups in the skillful performance of the snatching lift for the interest of the experimental group.

Al-Khayyat (2004), made a study aimed at reconnoitering the effect of a suggested educational method by using the internet in learning some basic skills in the tennis game, where the sample of study consisted of (40) students of the males, distributed between two groups: one disincentive upon which the educational programs are implemented by the classical method, and the other experimental, with which the interest was used, and upon which the researcher did design an electronic method and used experiments related to the fore-beat and the retro-beat and the beat of emission. The results of study indicated to the development of the experimental group level better than the disincentive group.

Al-Weesi (2003), prepared a study aimed at reconnoitering the effect of using the educational means (the video, slide project for transparencies and serial pictures) on the science of both activities of high jumping and long in "track and field" games. The sample of study consisted of (30) students of Al-Gimmah schools in the Directorate of Private Education, where it was divided into two groups: an experimental group, implemented the suggested educational program by using the educational means, meanwhile the disincentive group implemented the suggested educational program without using any educational means. The results of study indicated that there are differences with statistical indications in learning both activities of high jumping and long in "track and field" games for the interest of the experimental group.

\section{Methodology}

\subsection{Design}

The experimental method was used, because of its appropriateness to the nature of the study and by designing both equivalent groups.

\subsection{Population and Sample}

The population of study consisted of students of the table-tennis course in the first semester of the academic year 2012/2013 at Hashemite University. The sample of study consisted of (40) students of the table tennis course. They were chosen by the purposely method, distributed into two equal and equivalent groups, the first is experimental and the second is disincentive, due to the skillful level of the fore and retro-emission in the table-tennis. The basic variables of the sample were controlled (length and age) to do homogeneity of the sample, and students players within clubs and teams.

\subsection{Assisting Tools and Means:}

i. Showing video (L.G.).

ii. Showing television (L.G.).

iii. Tape-video, upon which recorded, the skillful performance of the fore and retro-emission.

iv. Tennis table.

v. Balls.

\subsection{Steps of Executing the Study}

1) Preparing vocabulary of education by the researcher in the educational program, depending on scientific sources, Appendix No. (1).

2) The experiment of the fore and the retro-skill of emission was used, because of its appropriateness in measuring ability and skill in the table tennis, the appendix No. (2).

3) The experiment of measuring accuracy in the skill of emission to appropriate with doing the study to give the student three attempts to perform the fore and retro-emission to be given a suitable result, the students were trained in assistance with trainers in the Department of Physical Activity and the Faculty of Physical Education. The educational program was given inside a closed hall.

4) Doing the investigational experiments related to the scientific treatments from part of truthfulness, steadiness and objectivity of this experiment after correcting it. 
5) Experiment of the sample of study.

6) Doing homogeneity for the sample of study.

7) Dividing the sample of study into two experimental groups.

8) Doing equivalence to the sample of study.

9) Doing the prior experiments.

10) Implementing the educational program of the fore and retro-skill of the emission.

11) Performing the posterior experiments.

12) Investigation of results.

\subsection{Investigational Experiments}

First: the experiment was done on a random sample from the community of study, consisted of (40) students at the beginning of the first semester of the university academic year (2012-2013), that is aiming at acknowledging the extent of the experiment appropriateness and the vocabulary of education in the educational program of students abilities and the problem that faces the researcher at preparing the study and appropriateness of experiment to the level of individuals of study.

Second: preparing the second investigational study, aiming at reconnoitering truthfulness, steadiness and objectivity, due to the following:

\subsection{Validity}

Validity of the content was done by showing the experiment to five experts, aiming at recognizing the appropriateness of the experiment to measure the skill of the fore and retro-emission. Results of experts indicated to validity of the experiment in measuring the skill of emission.

\subsection{Reliability}

Reliability was examined by test retest method with a period of ten days between the two tests. The reliability coefficient of connection was (0.90).

\subsection{Educational Program}

The researcher had prepared the educational program by employing education on the fore and retro-emission by trainers. Moreover, it was implemented as long as the first semester of the university academic

year (2012-2013) at two lectures a week, and every educational unit (45) minutes, including warming, and explanation of the sample of implementation and watching the video.

\subsection{Data Analyses}

SPSS was used to analyze the data. Means, standard deviations, and t-test were used to answer the hypotheses of the study.

\section{Results and Discussion}

Table 1. Means and standard deviations of the fore-emission of both disincentive and experimental groups

\begin{tabular}{lcccc}
\hline & \multicolumn{2}{c}{ Prior-emission } & \multicolumn{2}{c}{ Posterior-emission } \\
\hline & Mean & Standard deviation & Mean & Standard deviation \\
\hline Disincentive & 3.2 & .75 & 3.35 & .78 \\
Experimental & 3.4 & .81 & 4.47 & .75 \\
\hline
\end{tabular}

Table (1) shows differences in the arithmetic means between both groups: the experimental and disincentive to know if these were with statistical indication done by the researcher in experimenting these differences employing the (T- Test). 
Table 2. T-test on both groups the experimental and the disincentive for the fore-emission

\begin{tabular}{lcccc}
\hline Sources of variance & F & T & Degree of Freedom & Indication Level \\
\hline Program & .271 & .355 & 39 & .001 \\
\hline
\end{tabular}

Table (2) shows differences with statistical indication between the performances of both groups; the experimental and the disincentive at the level of indication $(\alpha \leq .05)$ ascribed to the program. In addition, referring to table (1) appears that the difference is for the interest of the experimental group. That results from the positive effect of the educational program on the skill of the fore-emission by using the video to students of the table-tennis course at the stage of Bachelor degree for choosing the (Test) of the corresponding samples, with both experiments; the prior and the posterior as it is illustrated in the table.

Table 3. Arithmetic means and standard deviations of the retro-emission of both groups; the disincentive and the experimental

\begin{tabular}{lcccc}
\hline \multirow{2}{*}{ Group } & \multicolumn{2}{c}{ Prior-emission } & \multicolumn{2}{c}{ Posterior-emission } \\
\cline { 2 - 5 } & Mean & Standard deviation & Mean & Standard deviation \\
\hline Disincentive & 3.3 & .78 & 3.38 & .79 \\
Experimental & 3.6 & .81 & 4.45 & .74 \\
\hline
\end{tabular}

Table (3) shows differences in the arithmetic means between the two groups; the experimental and disincentive to know if these differences were with statistical indication, the researcher made an experiment of these differences using the (T- Test).

Table 4. The experiment of the (T-test) on both groups; the experimental and the disincentive of the retro-emission

\begin{tabular}{ccccc}
\hline Sources of variances & F & T & Degree of Freedom & Level indication \\
\hline Program & .281 & .365 & 39 & .003 \\
\hline
\end{tabular}

Table (4) shows statistical differences between the performance of both groups; the experimental and disincentive at the level of indication $(\alpha \leq .05)$ ascribed to the program. In addition, referring to table No (1) appears that the difference is for the interest of the experimental group. It was cleared that the effect of using the video was for the interest of the experimental group in the retro-emission of the table tennis through differences between the two groups, for the level of indication is $(0.003)$.

Table 5. Arithmetic means and standard deviations of the fore-emission on the variable of age of both groups; the disincentive and the experimental

\begin{tabular}{ccccccc}
\hline \multirow{2}{*}{ Group } & \multicolumn{2}{c}{ Prior-emission } & \multicolumn{2}{c}{ Posterior-emission } \\
\cline { 2 - 7 } & Number & Age & Mean & $\begin{array}{c}\text { Standard } \\
\text { Deviations }\end{array}$ & Mean & $\begin{array}{c}\text { Standard } \\
\text { Deviation }\end{array}$ \\
\hline Experimental & 13 & $18-20$ & 3.3 & .75 & 3.70 & .79 \\
Group & 7 & $20 \&$ over & 3.1 & .77 & 3.00 & .78 \\
Disincentive & 14 & $18-20$ & 3.6 & .80 & 4.47 & .76 \\
Group & 6 & $20 \&$ over & 3.2 & .80 & 4.48 & .76 \\
\hline
\end{tabular}

There appears from table (5) differences in the arithmetic means between the two groups; the experimental and the disincentive on the variable of age. And to know if these differences were with statistical indication, the researcher made an experiment on three differences using the experiment of the (T- Test). 
Table 6. F-test for forehand serve experimental group

\begin{tabular}{ccccc}
\hline Sources of variances & F. & T. & Degree of Freedom & Level of indication \\
\hline Program & .276 & .358 & 39 & .605 \\
\hline
\end{tabular}

The previous table clears that there were no differences with statistical indication ascribed to the variable of age being $(0.605)$ bigger than $(\alpha \leq .05)$. And here the effect of the video (educational program) is clear on the fore-emission in the table tennis ascribed to the variable of age for the interest of the experimental group.

Table 7. Arithmetic means and standard deviations for the retro-emission on the variable of age for both groups the disincentive and the experimental

\begin{tabular}{ccccccc}
\hline \multirow{2}{*}{ Group } & \multicolumn{3}{c}{ Prior-emission } & \multicolumn{2}{c}{ Posterior-emission } \\
\cline { 2 - 7 } & number & Age & Mean & $\begin{array}{c}\text { Standard } \\
\text { Deviations }\end{array}$ & Mean & $\begin{array}{c}\text { Standard } \\
\text { Deviations }\end{array}$ \\
\hline Experimental & 10 & $18-20$ & 3.4 & .75 & 3.71 & .79 \\
Group & 10 & $20 \&$ over & 3.0 & .77 & 3.00 & .78 \\
Disincentive & 15 & $18-20$ & 3.7 & .80 & 4.48 & .76 \\
Group & 5 & $20 \&$ over & 3.1 & .80 & 4.45 & .76 \\
\hline
\end{tabular}

It is clear from the table differences in the arithmetic means between the two groups; the experimental and the disincentive on the variable of age. And to know if these differences were with statistical indication, the researcher experimented these differences using the experiment of (T- Test).

Table 8. F-test for backhand serve experimental group

\begin{tabular}{ccccc}
\hline Sources of variances & F & T & Degree of Freedom & Level of indication \\
\hline Program & .279 & .360 & 39 & .705 \\
\hline
\end{tabular}

The previous table shows that there are no differences with statistical indication ascribed to the variable of age in the retro-emission in the table tennis. This pinpoints to us the effect of the video (the educational program) on this skill for the interest of the experimental group, where the level of indication is $(0.705)$ as it is illustrated in the table.

\section{Conclusions}

1) The style of using the video has a positive effect in developing the skill of the fore-emission in the table tennis.

2) The style of using the video has a positive effect in developing the skill of the retro-emission in the table tennis.

3) The style of using video is the best in developing the skill of the fore-emission at a fewer rate than it is in the retro-emission.

\section{Recommendations}

In light of what study deduced, the researcher recommends the following:

1) Using the video in learning the basic skill of the table tennis has a positive effect in the operation of learning and mastery of the skill.

2) Necessity of using educational and assisting instruments at instructors and trainers in developing the basic skill in the table tennis.

3) Variation and using the educational means to learn the basic skills in the table tennis.

4) Necessity of performing more of scientific researches to cover all educational means on the basic skills as a whole for the table tennis. 


\section{References}

Al-As'ous, I. (2001). Effect of using a training program with assisting instruments in developing some basic skills in the basketball for beginners (14-16) years. Unpublished Master Degree theses, Yarmouk University, Jordan.

Alawi, M., \& Radwan, M. (1987). Skillful and psychological tests in the athletic field. Cairo: Darel Fikre Al-Arabi.

Al-Deiri, A. (1987). Comparison of the Activity of Classical and Training Method at the Skillful Level in the Basket Ball, publications of the University of Jordan. The First Athletic Conference, Amman, Jordan.

Al-Deiri, A., \& Abu Ruz, H. (1994). Effect of using the educational means on the skillful performance in lifting heavy weights for students of the faculty of physical education. Journal of Sciences and Arts, Hulwan University, 6(1), 122-134.

Al-Deiri, A., \& Al-Bataynah, A. (1987). Styles of Teaching the Physical Education. Irbid: Darel Amal for Publication and Distribution.

Al-Khayyat, O. (2004). Effect of suggested educational method by using the world information net (the internet) in learning some basic skills in the tennis game. Unpublished doctoral dissertation, University of Baghdad, Iraq.

Al-Masri, A. (1997). Effect of using some educational means on learning overturning side skill on the land apparatus. Unpublished Master theses, Al-Zagazeeg University, Egypt.

Al-Tameeli, S. (2002). The table tennis: The skillful and planning preparation. Amman: Dar Al-Fekr.

Al-Weesi, N. (2003). Effect of using the educational means on learning both activities of high jumping and long in track and field. Unpublished Master theses, Yarmouk University, Jordan.

Hussein, M. (1979). The Typical Evaluation in physical Education (part 1). Cairo: Darel Fikre Al-Arabi.

Mosston, M. (1981). Teaching Physical Education. London: Charles Merring publishing Group.

Mosston, M., \& Ashworth, S. (1994). Teaching physical education (4th ed.). USA: Macmillan College.

Moston, M. (1973). Teaching from command to discovery. Bebn, CA: Wadsworth Publishing Company.

Salameh et al. (2007). Effect of using the video in learning some basic skills in the volleyball. Abhath Al Yarmouk Journal, 23(4).

Salameh, I. (1999). Study of the relationships between the styles of instruction and motor learning: Application in the field of table of tennis. Unpublished doctoral dissertation, Bucharest University, Bucharest, Romania.

Salameh, I. (2004). Effect of using two styles in teaching some skills of the table tennis for the level of learning of the basic stage. Al-Manarah Journal,

Singer, R., \& Dick, W. (1980). Teaching physical education: A system approach. Boston: Houghton Miffin Company.

Singer, R., \& Peose, D. A. (1976). Comparison of discovery learning and guided instructional strategies on motor skill learning retention and transfer. Research quarterly. 38.

\section{Appendix A}

\section{Suggested Educational Program}

\begin{tabular}{|c|l|l|}
\hline Unit & Time & \\
\hline & & $\begin{array}{l}\text { Emission by the fore-racket. } \\
\text { Emission by the retro-racket. } \\
\text { Instructor (Trainer). }\end{array}$ \\
\hline First & $35 \mathrm{~ms}$ & $\begin{array}{l}\text { 1- Teaching students the correct hold of the racket. } \\
\text { 2- Hopping the ball with the front face of the racket with steadiness in the movement. } \\
\text { 3- Hopping the ball with the back face of the racket with steadiness in the movement. } \\
\text { 4- Throwing the emission at different parts of the table. }\end{array}$ \\
\hline
\end{tabular}




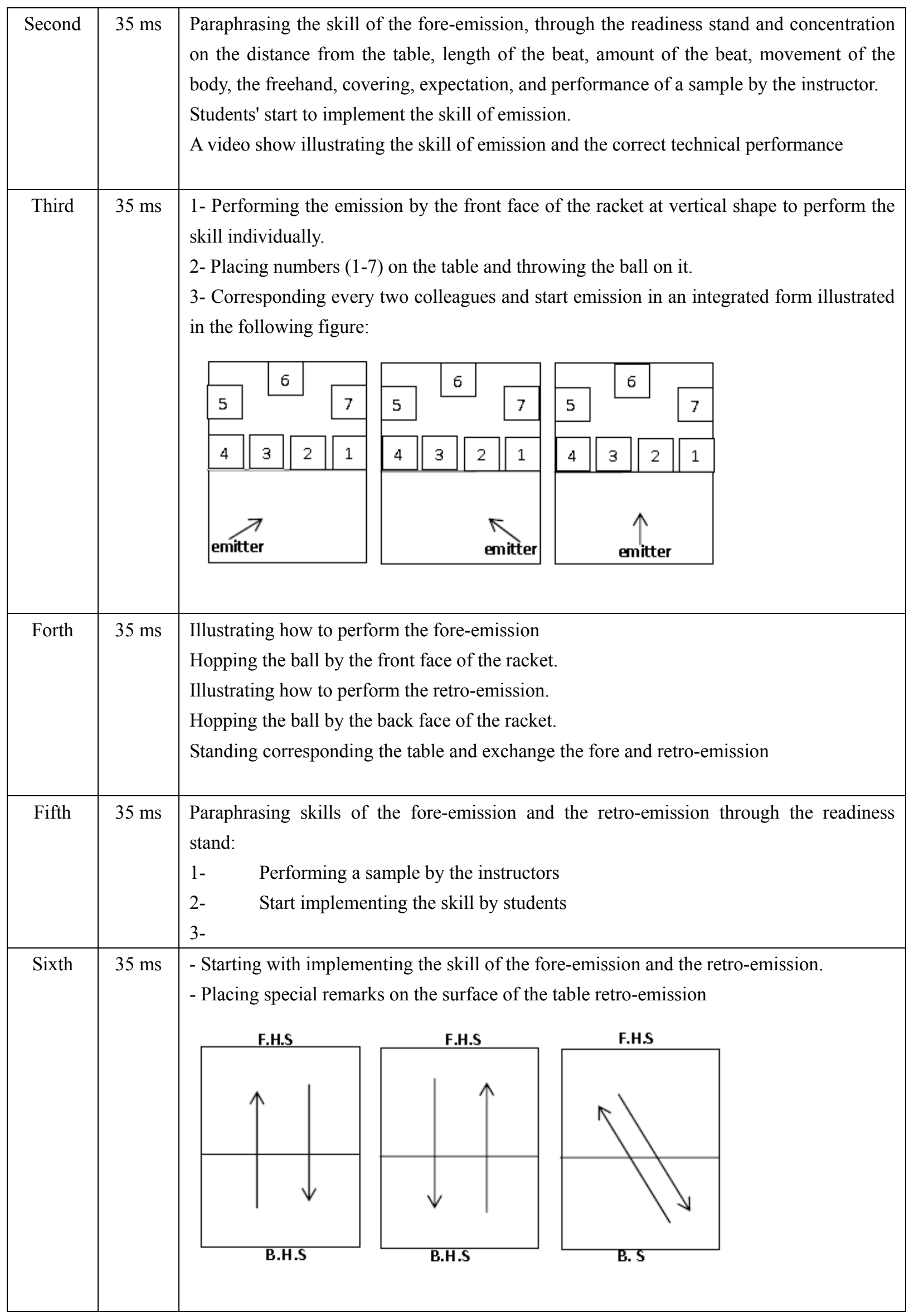




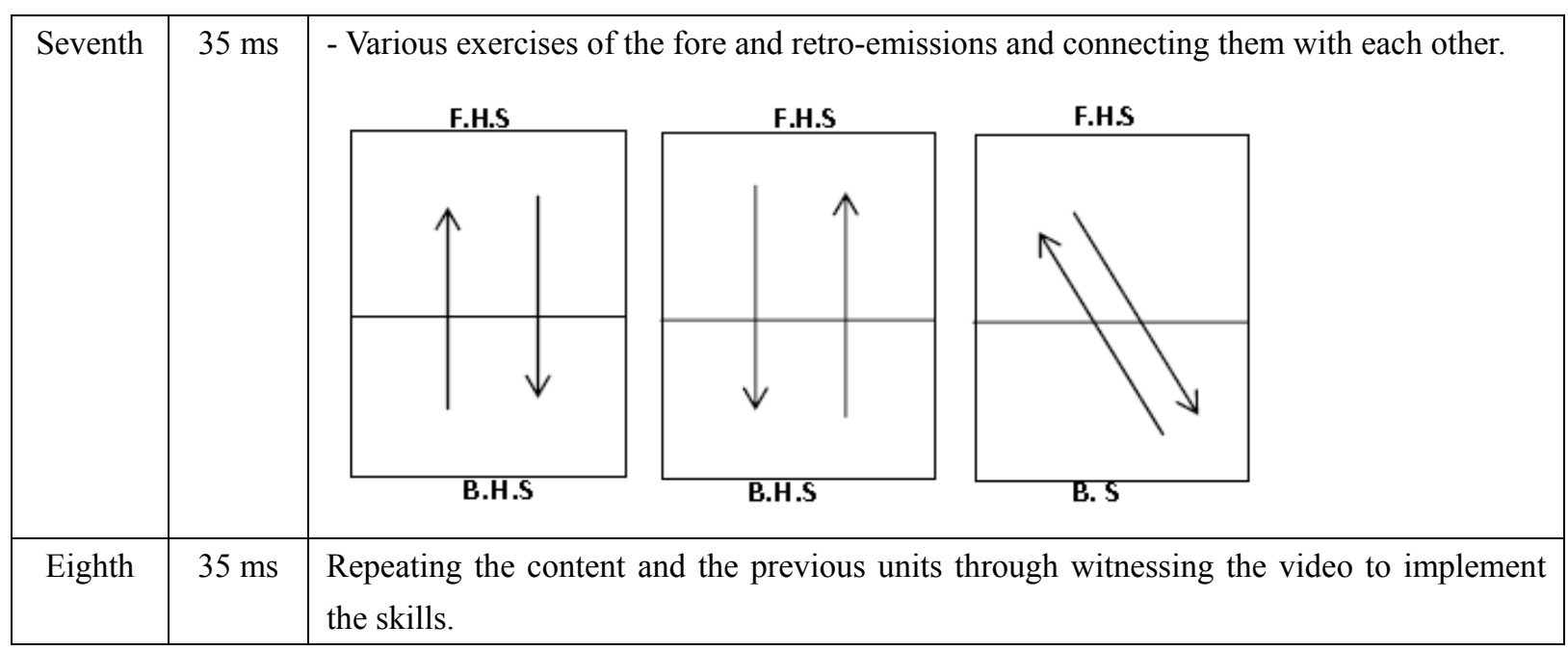

\section{Appendix B}

Name of Experiment: Experiment of Measuring the Skill of Ability of Emission in the Game of Table-Tennis

\section{Purpose of experiment:}

Measuring the skillful ability in the table tennis and classifying individuals in identical groups in accordance with their skillful abilities. And the results of the experiment are used as an indicator to pin-point to gaining in the table-tennis.

\section{Procedures of the experiment:}

Dividing the surface of the table into different sectors with the parts of the table, where numbers are illustrated from (1-7) in the parts of the table as a whole. Then the player stands in the corresponding direction of the table and with him the racket and the ball. The examiner begins giving the mark of start for the player, to beat the ball towards the sectors from (1-7), then count the number of times it reaches to the required number over the net by the player.

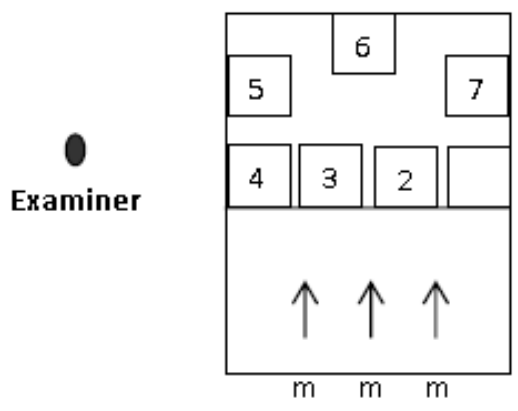

\section{Counting grades:}

The examiner stands beside the table and counts the performance of emission in the correct way in which the ball touches the numbered square on the surface of the table. And gives three consecutive attempts and counts the best attempt for the player.

\section{Copyrights}

Copyright for this article is retained by the author(s), with first publication rights granted to the journal.

This is an open-access article distributed under the terms and conditions of the Creative Commons Attribution license (http://creativecommons.org/licenses/by/3.0/). 